\title{
我国干旱区深厚大气边界层与陆面热力过程的 关系研究
}

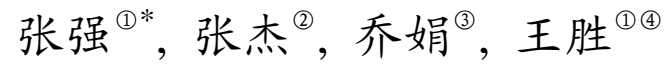

(1) 甘肃省干旱气候变化与减灾重点实验室, 中国气象局干旱气候变化与减灾重点开放实验室, 中国气象局兰州干旱气象研究所, 兰州 730020;

(2) 气象灾害省部共建教育部重点实验室, 南京信息工程大学, 南京 210044;

(3) 西安市气象局, 西安 401147;

(4) 兰州大学大气科学学院, 兰州 730000

*E-mail: zhangqiang@cma.gov.cn

收稿日期: 2010-06-09; 接受日期: 2010-12-19

国家自然科学基金重点项目(批准号: 40830957, 40805009)资助

摘要大气边界层是地球大气重要物理特征之一。千旱气候背景下的大气边界层特征 与人们以往对典型大气边界层的认识有很大不同，其形成机制也比较特殊. 本文利用冬、

夏两季典型时段在极端干旱区敦煌开展的大气边界层和陆面过程综合观测试验，对大气 边界层厚度与净辐射、地-气温差和感热通量等陆面热力因素的日变化特征进行了对比分 析, 研究了大气边界层的发展和维持衰退过程与陆面热力和动力过程的关系, 发现发展过 程消耗的能量要比维持衰退过程高得多, 而且进入残余层后对流边界层发展对陆面热力 作用更敏感，发展也更迅速．风速的动力作用对大气边界层发展也有一定的影响，尤其对 冬季稳定大气边界层影响较大. 极强的陆面热力作用是我国干旱区形成深厚大气边界层 的主导因素.

关键词

干旱区

深厚大气边界层 发展和维持过程 陆面热力作用 主导因素
大气边界层是地球大气最主要的物理特征之一, 它与天气、气候的形成和演化密切相关. 因此, 大气 边界层厚度一直是大气数值模式和大气环境评价的 重要物理参数之一. 早期研究曾普遍认为白天对流 边界层厚度一般为 $1000 \mathrm{~m}$ 的量级, 夜间稳定边界层 可能只有 $100 \mathrm{~m}$ 的量级 ${ }^{[1]}$. 但最近十多年对一些特殊 地理环境和极端气候背景下的大气边界层的研究已 逐渐突破了以往人们对大气边界层特征的认识 ${ }^{[2 \sim 5]}$. 1999 年 Takemi 等 ${ }^{[6]}$ 曾利用常规气象探空资料, 分析
了中国西北地区河西走廊干旱区的大气边界层特征, 从其残余层特征推测出能够出现超过 $4 \mathrm{~km}$ 厚的对流 边界层. 几乎在同期, 张强等 ${ }^{[7]}$ 在 2000 年的 NWC-ALIEX 试验中也通过实际观测发现: 西北极端 干旱区敦煌夏季晴天白天能够形成超过 $4 \mathrm{~km}$ 的对流 边界层; 并且夜间稳定边界层也可超过 $1 \mathrm{~km}^{[8]}$. 为了 进一步证实这种观测结果的可靠性和普遍性, 乔娟 等 ${ }^{[9]}$ 和 Zhang 等 ${ }^{[10]}$ 专门在敦煌地区进行了大气边界 层观测试验研究. 该试验使用比较先进的 L 波段雷达

英文引用格式: Zhang Q, Zhang J, Qiao J, et al. Relationship of atmospheric boundary layer depth with thermodynamic processes at the land surface in arid regions of China. Sci China Earth Sci, 2011, doi: 10.1007/s11430-011-4207-0 
探空系统和卫星遥感反演温度廓线技术, 证实该地 区盛夏晴天出现深厚对流边界层具有一定的普遍性; 并发现冬季大气对流边界层要低得多, 还不到夏季 的 1/4. 在类似干燥下垫面的非洲撒哈拉沙漠中, Marsham 等 ${ }^{[11]}$ 观测到了高达 $5.5 \mathrm{~km}$ 的深厚对流边界 层, 并且其残余层特征也十分突出. 深厚大气对流边 界层与剧烈的太阳辐射等气候背景和极端干燥的地 表环境等有关 ${ }^{[12 ~ 18]}$.

目前对我国西北干旱区深厚大气边界层形成机 理的研究还比较初步, 尤其是对陆面过程在其中的 作用机制了解十分有限, 这大大限制了对深厚大气 边界层与天气气候相互作用规律的认识, 也影响了 深厚大气边界层特征的大气数值模式参数化改进. 本文试图利用在敦煌开展的大气边界层观测试验 ${ }^{[19]}$ 获得的大气边界层和陆面过程综合观测资料, 系统 分析大气边界层发展和维持衰退过程中陆面热力过 程的作用特征, 进一步深入探讨干旱地区出现深厚 大气边界层的物理原因.

\section{1 观测环境与资料、方法介绍}

敦煌大气边界层观测试验 ${ }^{[9]}$ 是国家自然科学基 金支持的一次大气边界层和陆面过程综合观测试验, 该观测试验区位于 $40^{\circ} 10^{\prime} \mathrm{N}, 94^{\circ} 31^{\prime} \mathrm{E}$, 地处我国西北 干旱区中心地带, 海拔高度为 $1140 \mathrm{~m}$; 是中纬度气 候带上典型的极端干旱区之一, 年平均降水不到 40 $\mathrm{mm}$; 其日照充足, 日照百分率高达 $75 \%$, 日照时数 多达 $1114.2 \mathrm{~h}$; 且蒸发潜力巨大, 年平均蒸发量高达 $3400 \mathrm{~mm}$; 年地面平均温度为 $12^{\circ} \mathrm{C}$, 冬、夏平均温度 相差 $40^{\circ} \mathrm{C}$ 以上; 地面年平均风速约为 $2.7 \mathrm{~m} \mathrm{~s}^{-1}$.

图 1 是该观测试验的地理环境和观测场地, 观测 试验区在距敦煌市绿洲西侧 $7 \mathrm{~km}$ 的双墩子戈壁滩上, 位于绿洲的上风方向, 能量、水分和物质交换基本不 受绿洲气候的影响, 因此观测结果代表了该地区荒 漠戈壁陆面过程特征. 观测场设有超声浴动系统的 近地层通量观测和地面辐射平衡观测设备. 超声浴 动仪为 Compbell 公司生产的 CSAT3 型, 架设高度为 $2.5 \mathrm{~m}$; 辐射分量观测仪器为美国 Eppley 公司生产的 PSP 型, 架设高度为 $1.5 \mathrm{~m}$. 同时, 在敦煌市东郊的敦 煌气象站内设有 $\mathrm{GFE}(\mathrm{L}) 1$ 型二次测风雷达和 GTS1
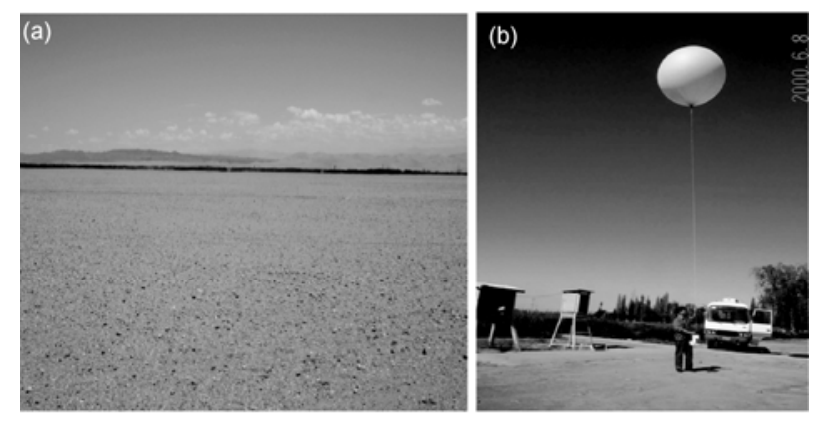

图 1 敦煌大气边界层试验的地理环境(a)和观测现场(b)

型数字式探空仪组成的 $\mathrm{L}$ 波段雷达探空系统, 观测的 边界层气象要素包括温度、湿度、风速、风向、气压 等, 探空高度保持在 $8680 \mathrm{~m}$ 以上, 每隔 $10 \mathrm{~m}$ 记录一 次探空观测数据. 观测时段分夏、冬两期, 分别为 2006 年 6 月 28 日 7 月 17 日和 2007 年 1 月 1 日 1 月 10 日; 每日观测 8 次, 分别为北京时 $7,9,11,13$, $15,17,19,21$ 时.

$\mathrm{L}$ 波段雷达大气探空系统是我国自行研制的新 型高空气象探测设备 ${ }^{[20,21]}, 2005$ 年开始投入业务使用. 该系统使用的 GTS1 数字式电子探空仪与之前使用的 “59”型机械式探空仪相比, 对温度、气压、湿度的测 量范围和测量精度均有明显改进, 而且时、空分辨率 明显提高. 适于干旱地区大气边界层的观测研究.

本文所用资料来自 2006 2007 年期间在西北干 旱区敦煌进行的大气边界层观测试验 ${ }^{[9,19]}$. 为了对比 分析大气边界层空间分布的差异，在酒泉、民勤、榆 中、平凉等四地开展了同期大气边界层观测. 在观测 期间, 2006 年 7 月 5 7 日有一次降水过程, 2007 年 1 月 2 日前后是阴天, 其他时间基本为晴空天气. 在干 旱地区，热力作用在大气边界层过程中更为突出, 边 界层位温廓线特征更加显著, 所以本文用位温廓线 法来确定边界层厚度 ${ }^{[22,23]}$. 具体方法是：白天 $(11,13$, 15,17 时), 从地面最早出现的强度超过 $0.3^{\circ} \mathrm{C}(100$ $\mathrm{m})^{-1}$ 的大气逆温层的底部以下范围确定为对流边界 层高度, 或者将位温、比湿随高度几乎不变的厚度作 为混合层的最大高度，如图 2 (a); 夜间 $(7,9,19,21$ 时), 将贴地且强度超过 $0.4^{\circ} \mathrm{C}(100 \mathrm{~m})^{-1}$ 逆位温层范 围确定为稳定边界层高度 ${ }^{[14]}$, 如图 2(b). 夜间逆温顶 盖以上基本保持近中性层结并在更上层又一较弱逆 温顶盖一下的范围为残余层 ${ }^{[14,15]}$. 

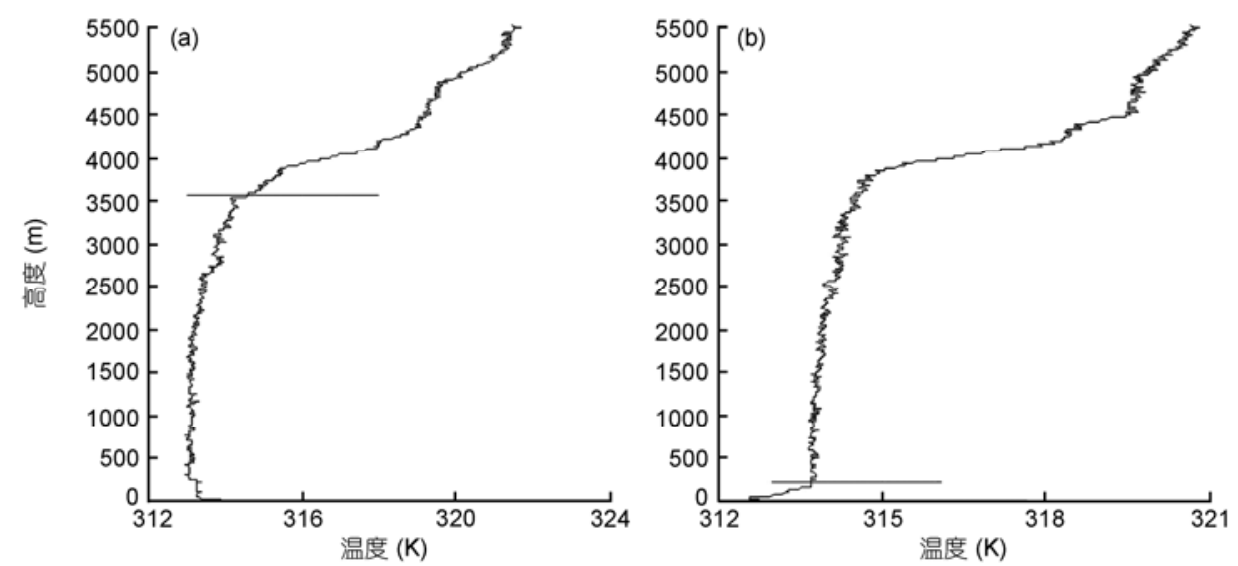

图 2 用位温廓线法确定白天对流边界层高度 $(\mathbf{a})$ 和夜间稳定边界层高度(b)

\section{2 结果分析}

\section{1 大气边界层厚度与陆面热力因素的日变化特 征比较}

陆面热力过程主要是指太阳辐射能量在陆面转 化成热能, 加热地表并向大气和土壤传输的过程. 这 其中, 陆面辐射收支形成的净辐射是陆面热能形成 的基础, 地表辐射加热(或冷却)形成的地-气温差是 大气边界层热对流(或逆温层)产生的热动力, 近地层 湍流感热输送是大气边界层热对流(或逆温层)发展 的热量维持机制. 所以, 从物理上讲, 大气边界层形 成和发展与地表净辐射、地-气温差和近地层感热通 量密切相关.

图 3 是观测期间晴天平均地表净辐射、地-气温 差和感热通量的日变化与大气边界层厚度日变化的 对比. 为了便于分析, 在图 3 中将对流边界层厚度表 示为正值, 将稳定边界层厚度表示为负值. 从图中可 看出, 无论是夏季还是冬季, 净辐射、地-气温差和感 热通量日变化过程与大气边界层厚度均有比较好的 对应关系, 当白天净辐射越大、地-气温差越剧烈、湍 流感热量输送越强, 对流边界层就越深; 反之, 当夜 间净辐射赤字越大、地气逆温越剧烈、负热量输送越 强, 稳定边界层就越厚. 不过, 大气边界层的发展要 比净辐射晚大约 $2 \mathrm{~h}$, 比地-气温差和感热通量晚大约 $1 \mathrm{~h}$. 这种边界层发展滞后现象与地表辐射能量分配 和转化以及在大气中的输送过程需要一定响应时间 有关 ${ }^{[24]}$, 所以本文后面将把 3 个陆面热力变量的位相 调整到与大气边界层厚度变化同步后进行分析.

\section{2 大气边界层发展和维持衰退过程与陆面热力 因素的关系}

由于陆面热力过程在大气边界层演变过程中的 不同作用，本节将每日大气对流边界层(或稳定边界 层)厚度达到峰值以前的增加阶段作为对流边界层 (或稳定边界层)的发展阶段, 将峰值以后的稳定或降 低阶段作为对流边界层(或稳定边界层)的维持衰退 阶段.

\subsection{1 净辐射与对流边界层和稳定边界层发展和 维持衰退的关系}

图 4(a)是夏季净辐射与对流边界层发展(左)和维 持衰退(右)的关系. 从图 4(a)中可以看出, 在对流边 界层发展阶段, 边界层厚度对地表辐射的依赖非常 明显. 在厚度没有超过 $500 \mathrm{~m}$ 左右之前, 对流边界层 随净辐射增加发展很慢; 在厚度超过 $500 \mathrm{~m}$ 以后，对 流边界层发展很迅速; 当厚度超过 $2500 \mathrm{~m}$ 以后发展 又变得缓慢一些. 这意味着在热对流还没有完全冲 破夜间形成的稳定边界层之前，对流边界层发展阻 力较大, 需要消耗较多能量来克服稳定层结的约束; 而一旦进入残余层范围, 对流边界层发展比较顺畅, 消耗的能量要少得多; 但超出残余层时, 又会受到弱 逆温顶盖的限制 ${ }^{[15]}$. 从图 4(a)中还可以看出, 大约在 净辐射强度超过 $300 \mathrm{~W} \mathrm{~m}^{-2}$ 以上, 对流边界层一般才 能突破夜间形成的稳定边界层的限制. 在对流边界 层维持衰退阶段, 边界层厚度随净辐射减弱缓慢的 收缩, 对辐射能量的依赖不如发展阶段强, 似乎热惯 性在一定程度上发挥着作用。可见，正是由于极端干 

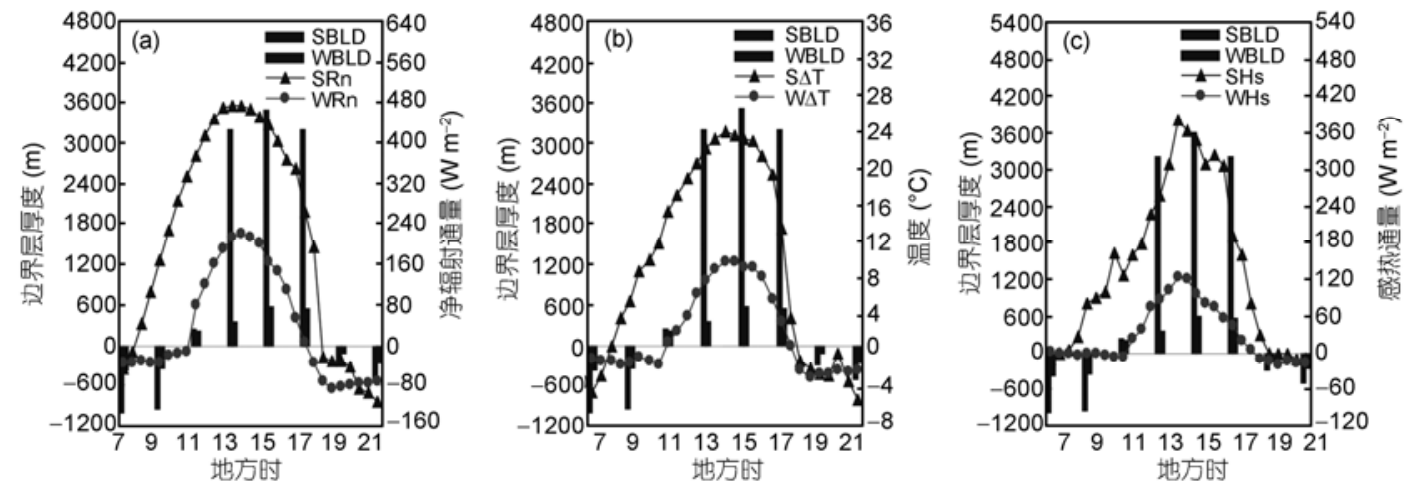

图 3 净辐射 $(\mathbf{a})$ 、地-气温差(b)和感热通量(c)日变化与大气边界层厚度的关系 对流边界层用正值表示, 稳定边界层用负值表示
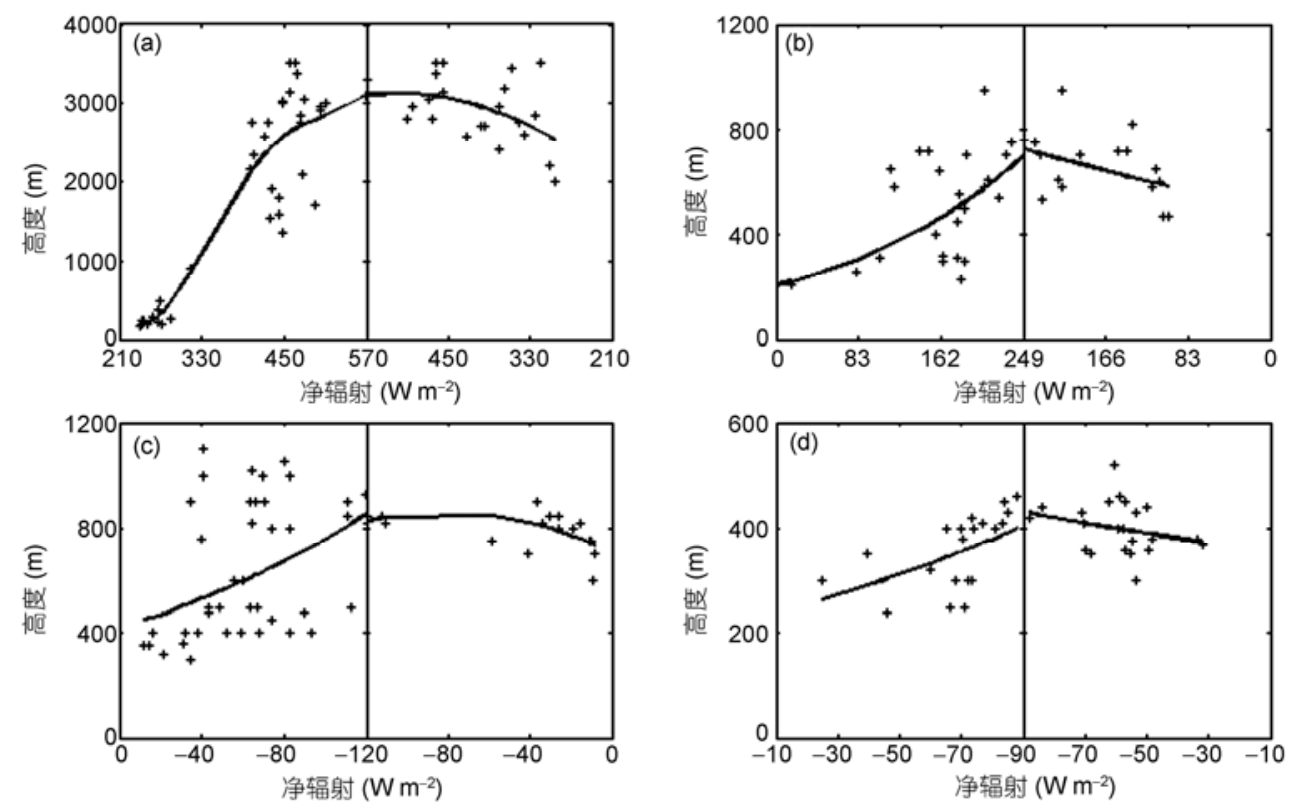

图 4 夏季和冬季地表净辐射与对流边界层和稳定边界层发展与维持衰退的关系

(a) 夏季净辐射与对流边界层发展和维持衰退的关系; (b) 冬天净辐射与对流边界层发展和维持衰退的关系; (c) 夏季地表净辐射与夜间稳定 边界层发展和维持衰退的关系; (d) 冬天地表净辐射与稳定边界层发展和维持衰退的关系

早荒漠区夏季能够出现超过 $400 \mathrm{~W} \mathrm{~m}^{-2}$ 的地表高净辐 射状态，为对流边界层发展奠定了能量利用基础，促 使夏季白天可以发展出 $3000 \mathrm{~m}$ 以上甚至接近 $4000 \mathrm{~m}$ 的深厚对流边界层.

图 4(b)给出冬天净辐射与对流边界层发展(左)和 维持衰退(右)的关系,虽然不如夏季的好, 但总体趋 势有一定类似，对流边界层厚度发展到大约 $300 \mathrm{~m}$ 之 后对净辐射的变化要更敏感一些. 这同样说明突破
夜间稳定边界层以后, 残余层的大气热力环境对流 边界层发展要更有利一些 ${ }^{[15]}$. 但很显然, 冬季残余层 作用远不如夏季明显.

图 4(c)是夏季地表净辐射与夜间稳定边界层发 展(左)和维持衰退(右)的关系. 由图 4(c)可以看出, 随 着地表辐射收支赤字增加, 地表辐射冷却效应增强, 逆温层范围向上扩展，稳定边界层会不断发展．同时， 在维持衰退阶段，随着负净辐射值的减弱，稳定边界 
层厚度起初基本维持稳定不变; 直到负净辐射值减 弱到大约 $-60 \mathrm{~W} \mathrm{~m}^{-2}$ 以下, 稳定边界层才会逐渐收缩 趋势. 同样可以看出, 正是由于极端干旱荒漠区夏季 夜间净辐射赤字非常显著, 最强时高达 $-120 \mathrm{~W} \mathrm{~m}^{-2}$, 为发展接近 $1000 \mathrm{~m}$ 的深厚稳定边界层提供了能量机 制. 冬天地表净辐射与稳定边界层(图 4(d))发展(左) 和维持衰退的关系(右)也与夏季类似, 但稳定边界层 发展随净辐射变化总体更缓慢. 并且, 在同样的净辐 射条件下, 冬季发展的稳定边界层不如夏季的深厚, 这可能与夏季地表更干燥有关.

\subsection{2 地-气温差与对流边界层和稳定边界层发展 和维持衰退的关系}

地表辐射盈余或赤字会引起地表加热或降温, 产生地-气温差, 形成热动力, 驱动大气边界层发展. 在图 5(a)中, 给出了夏季地-气温差与白天对流边界 层发展(左)和维持衰退(右)的关系, 地温为地表温度, 气温为 $3 \mathrm{~m}$ 高的温度. 该图表明, 当地-气温差大约 超过 $10^{\circ} \mathrm{C}$ 以后, 对流边界层就能够进入残余层, 并 迅速发展; 当地-气温差大约超过 $20^{\circ} \mathrm{C}$ 以后, 就可能 发展出 $3000 \mathrm{~m}$ 以上的深厚对流边界层. 很清楚, 地 表高辐射盈余产生的剧烈地-气温差是发展深厚对流 边界层的关键热动力. 在对流边界层维持衰退阶段, 与净辐射的情况相比, 对流边界层厚度随地-气温差 变化更加明显. 从图 5(b)冬季地-气温差与白天对流 边界层发展(左)和维持衰退(右)的关系看, 在地-气温 差大约达到 $5^{\circ} \mathrm{C}$ 或边界层厚度突破 $300 \mathrm{~m}$ 以后对流边 界层发展要明显快一些.

图 5(c)是夏季地-气温差与夜间稳定边界层发展 (左)和维持衰退(右)的关系. 很显然, 随着地表辐射 冷却效应增强, 地-气逆温差增加, 在机械湍流扩散 作用下大气稳定边界层不断向上扩展, 地-气逆温差 超过 $-5^{\circ} \mathrm{C}$ 以后稳定边界层发展相对比较缓慢. 值得 注意的是, 也有一些比较深厚稳定边界层个例却出 现在地-气逆温差比较小情况下. 在维持和衰退阶段, 随着地-气逆温的减弱, 稳定边界层一直保持缓慢收 缩趋势, 这与对流边界层很不同. 冬季地-气温差与 稳定边界层发展和维持衰退的关系不太明显, 地-气 温差对稳定边界层只有微弱的影响. 这在一定程度 上表明, 无论夏季还是冬季, 夜间风切变引起的机械 湍流作用往往比较显著 ${ }^{[8,12]}$, 在稳定边界层发展过程 中边界层动力作用和陆面热力作用同时存在, 在冬
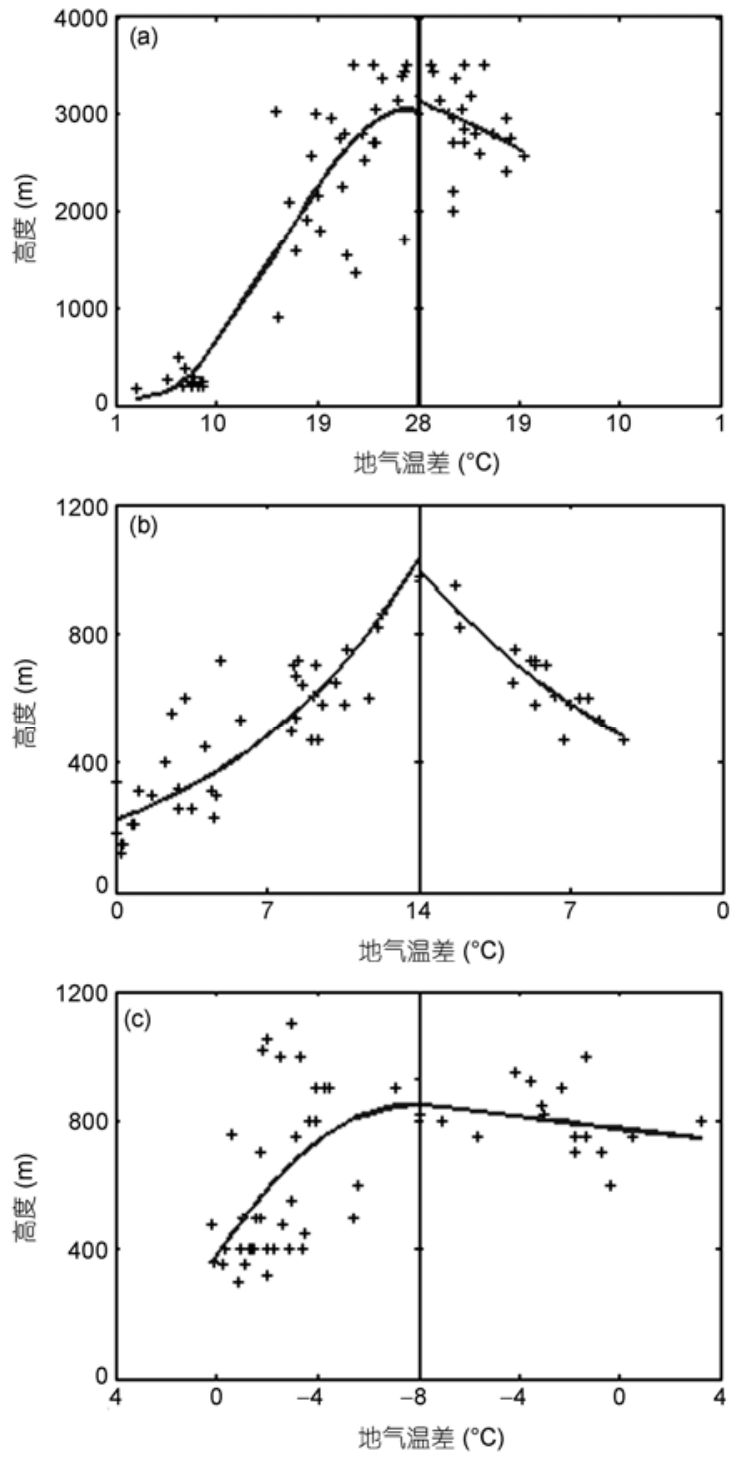

图 5 夏季和冬季地-气温差与对流边界层和稳定边界层发 展与维持衰退的关系

(a) 夏季地-气温差与对流边界层发展和维持衰退的关系; (b) 冬天 地-气温差与对流边界层发展和维持衰退的关系; (c) 夏季地-气温差 与夜间稳定边界层发展和维持衰退的关系; (d) 冬天地-气温差与稳 定边界层发展和维持衰退的关系

季会以动力作用为主导, 所以冬季稳定边界层与陆 面热力因素的关系要更差一些.

\subsection{3 感热通量与对流边界层和稳定边界层发展 和维持衰退的关系}

大气热力边界层的发展和维持主要依靠感热通 量对热量的输送来维持 ${ }^{[25 ~ 28]}$. 图 6(a)是夏季地表感热 

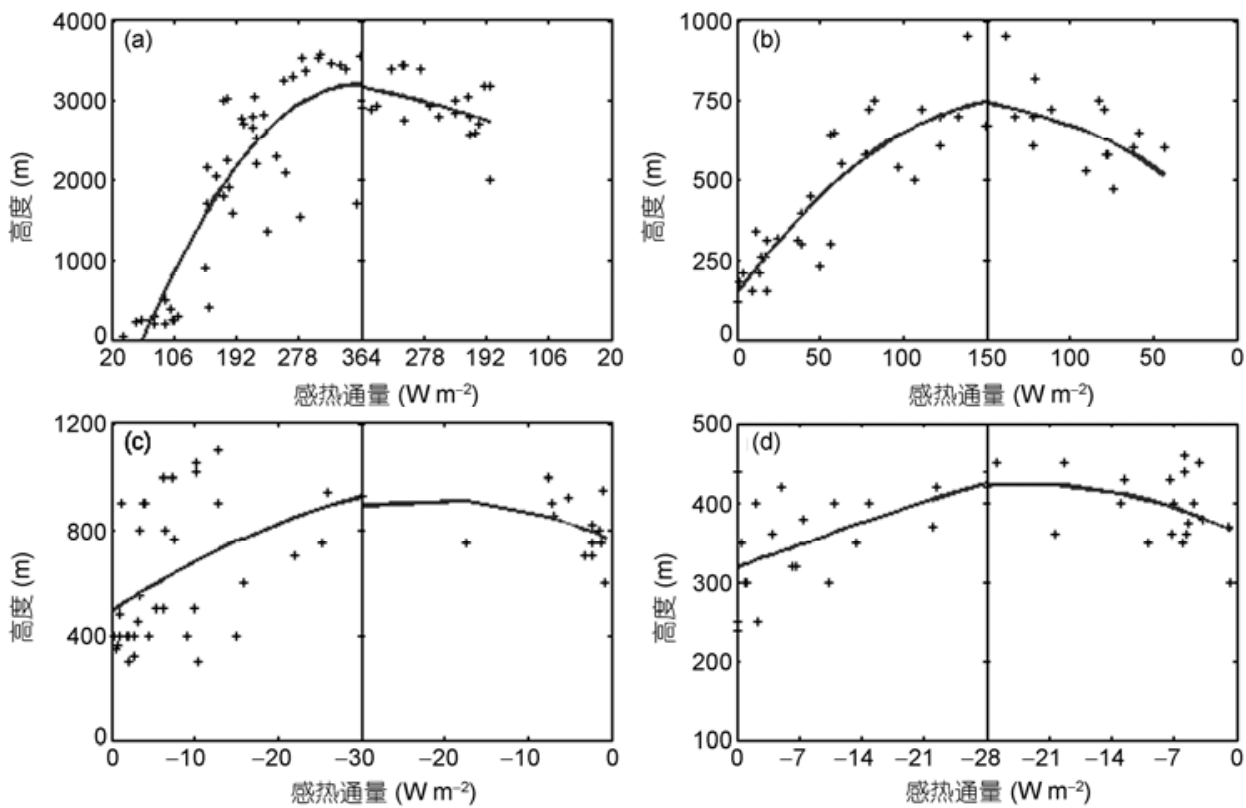

图 6 夏季和冬季感热通量与对流边界层和稳定边界层发展与维持衰退的关系

(a) 夏季感热通量与对流边界层发展和维持衰退的关系; (b) 冬天感热通量与对流边界层发展和维持衰退的关系; (c) 夏季感热通量与夜间稳 定边界层发展和维持衰退的关系; (d) 冬天感热通量与稳定边界层发展和维持衰退的关系

通量与对流边界层发展(左)和维持衰退(右)的关系. 我们很容易看出, 与净辐射和地-气温差的情况类似, 在地表感热通量大约超过 $100 \mathrm{~W} \mathrm{~m}^{-2}$ 以后对流边界层 就可以突破稳定边界层进入残余层, 然后随感热通 量增大迅速发展; 在地表感热通量大约超过 $250 \mathrm{~W}$ $\mathrm{m}^{-2}$ 以后就会发展出 $3000 \mathrm{~m}$ 以上的深厚对流边界层. 在对流边界层维持衰退阶段, 边界层厚度随地表感 热通量减弱收缩要比随净辐射减弱收缩得更明显, 但不如随地-气温差减弱收缩得快. 图 6(b)冬季地表 感热通量与对流边界层发展(左)和维持衰退(右)的关 系很显然要比地表净辐射的相关更好一些, 并且边 界层发展和衰退随感热通量的变化过程比较平稳. 图 6(c)夏季地表感热通量与夜间稳定边界层发展(左) 和维持衰退(右)的关系似乎更不理想, 仅表现出一个 大致趋势, 并且仅在较弱的负感热通量条件下就可 以发展出 $800 \mathrm{~m}$ 左右比较深厚的稳定边界层. 图 6(d) 冬季地表感热通量与白天对流边界层发展(左)和维持 衰退(右)的关系与夏季的趋势比较类似, 并且在负感 热通量低于 $-20 \mathrm{~W} \mathrm{~m}^{-2}$ 之前边界层厚度基本维持不变. 但冬季稳定边界层厚度总体要比夏季低得多.

\subsection{4 大气边界层发展和维持过程与边界层风速 的关系}

除了陆面热力作用而外, 大气边界层自身的动 力因素还会引起机械湍流, 也能在一定程度上影响 大气边界层的形成和发展. 其中, 风速是大气边界层 最主要的动力因素.

分析表明，夏季边界层最大风速与白天对流边 界层发展和维持衰退过程似乎没有明显的关系. 如 图 7(a)所示, 在夏季, 夜间稳定边界层发展(左)与边 界层最大风速的关系比较密切, 但在风速大约超过 $10 \mathrm{~m} \mathrm{~s}^{-1}$ 前并不敏感，而当风速超过 $10 \mathrm{~m} \mathrm{~s}^{-1}$ 后夜间 稳定边界层厚度会随风速增大迅速扩展. 由此可见, 夜间发展比较深厚的稳定边界层与较强风速引起的 强机械湍流扩散有一定关系，而大风速的出现一般 很可能与夜间低空急流有关，这与上一节对陆面热 力作用的分析结论是一致的. 所以干旱荒漠区出现 比较深厚的稳定边界层与以往在该地区经常发现的 低空急流有关 ${ }^{[8]}$. 不过, 在图 7(a)维持衰退阶段(右), 稳定边界层似乎与风速也没有太明显的关系，仅随 风速减弱有轻微收缩.

图 7(b)冬季边界层最大风速与白天对流边界层 

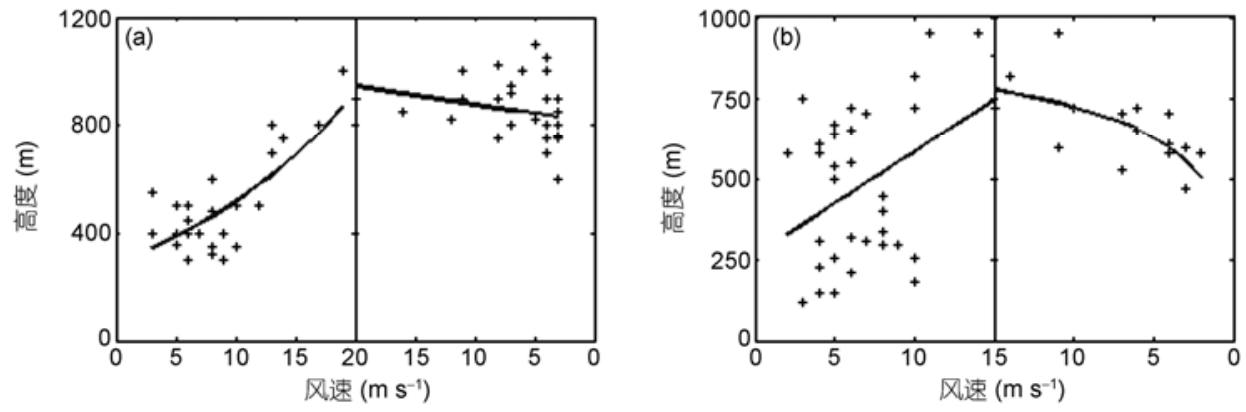

图 7 夏季边界层最大风速与稳定边界层发展与维持衰退的关系(a)和冬季边界层最大风速与对流边界层发展 与维持衰退的关系 $(\mathbf{b})$

发展(左)和维持衰退(右)似乎存在一定的关系。风速 较大时边界层发展比较深厚, 并且, 在维持衰退阶段, 对流边界层在风速小于 $8 \mathrm{~m} \mathrm{~s}^{-1}$ 后收缩更明显一些. 这可能是由于冬季热力作用较弱, 风速切变引起的 机械湍流的贡献比较容易突现出来，而夏季则是以 热力作用为主导.

\subsection{5 天气过程对大气边界层厚度的影响}

受太阳辐射高度角日变化的影响, 地表净辐射 以及感热通量、以及地表温度都具有明显的日变化特 征, 相应地, 热对流所引起的大气边界层厚度也具有 明显的日变化特征. 降水和阴天等天气过程会影响 到达地面的太阳辐射, 进而造成地面能量分配改变 及边界层厚度的变化. 图 8 给出降水过程和阴天前后 夏季和冬季每日最大对流边界层(CBL)和每日最大稳 定边界层(SBL)变化, 其中, 2006 年 7 月 5 号出现微量 降水, 6 号和 7 有为阴天, 冬季 1 月 2 号为阴天, 无降 水产生. 由图 8 可知, 不论在冬季还是夏季的阴天和 降水天, 白天最大对流边界层厚度都有所减小, 阴天 过后, 最大对流边界层厚度迅速升高. 这种边界层变 化一方面因为阴天太阳辐射到达地面的总量较少, 产生的热对流有所减小; 降水天使得地面湿度增加, 地表潜热通量增加, 而感热通量减小, 热对流有所减 小, 限制了对流边界层的发展; 另一方面, 如果阴天 出现低云, 混合层水汽增大, 云系会抑制对流边界层 的发展, 最终造成相对较低的对流边界层. 同样地, 在阴天和雨天, 最大夜间的稳定边界层也相应减小, 与最大对流边界层厚度相比, 最大稳定边界层厚度 变化幅度相对较小.

\section{3 西北干旱-半干旱区大气边界层空间分布差异}

对加强观测的 5 个不同降水区域的大气边界层
高度对比表明，敦煌、民勤、酒泉、榆中和平凉的年 平均降水量分别为 39.9, 113.6, 87.7, 289.9 和 511.2 $\mathrm{mm}$, 不同降水条件下大气边界层厚度有显著差异. 图 9 为各季节最大对流边界层厚度与最大稳定边界 层厚度的分布特征, 由图可见, 各个季节对流边界层 和稳定边界层的厚度基本随降水量的增加而降低. 夏季敦煌和平凉地区对流边界层平均高度相差约 $1100 \mathrm{~m}$, 最大稳定边界层厚度则相差 $500 \mathrm{~m}$ 左右, 冬 季这两个地区最大边界层厚度较为接近, 对流边界 层和稳定边界层的平均高度差值分别仅为 $130 \mathrm{~m}$ 和 $170 \mathrm{~m}$ 左右. 降水较少的极端干旱区敦煌的大气边界 层最为深厚, 这可能因为敦煌日照时数更长, 接收的 太阳辐射更为充足, 地表获得的能量更多, 地面对大 气的加热作用更为显著, 为边界层的发展创造了良 好的热力环境. Randal 等 ${ }^{[29]}$ 的研究也表明, 干旱地区 存在类似于大洋暖池对厄尔尼诺一样的贡献，它是 陆地上的“热块”，这些地区的地表能量过程和大气 对流的发展对土壤湿度十分敏感, 即较小的土壤湿 度空间差异也许会造成地表能量和大气对流特征比 较明显的差异. 这样就比较容易理解这五个地区大 气边界层高度空间分布特征的差异.

综上所述，与其他四个地区相比，降水最少的极 端干旱区敦煌具有更充足的能量基础，具备能够发 生更强湍流和对流运动的动力条件, 同时最为干早, 造成地表有更强的白天辐射加热和夜间辐射冷却能 力, 这些因素都有利于其超常厚度大气边界层的形 成和发展。

图 9 也表明, 五个地区大气边界层高度均在夏季 达到最大, 春季次之, 冬季最低. 热力因子是推动边 界层发展的重要因素, 其中太阳辐射是一切能量的 源泉. 夏季太阳辐射最强烈, 能量最充足, 热力作用 

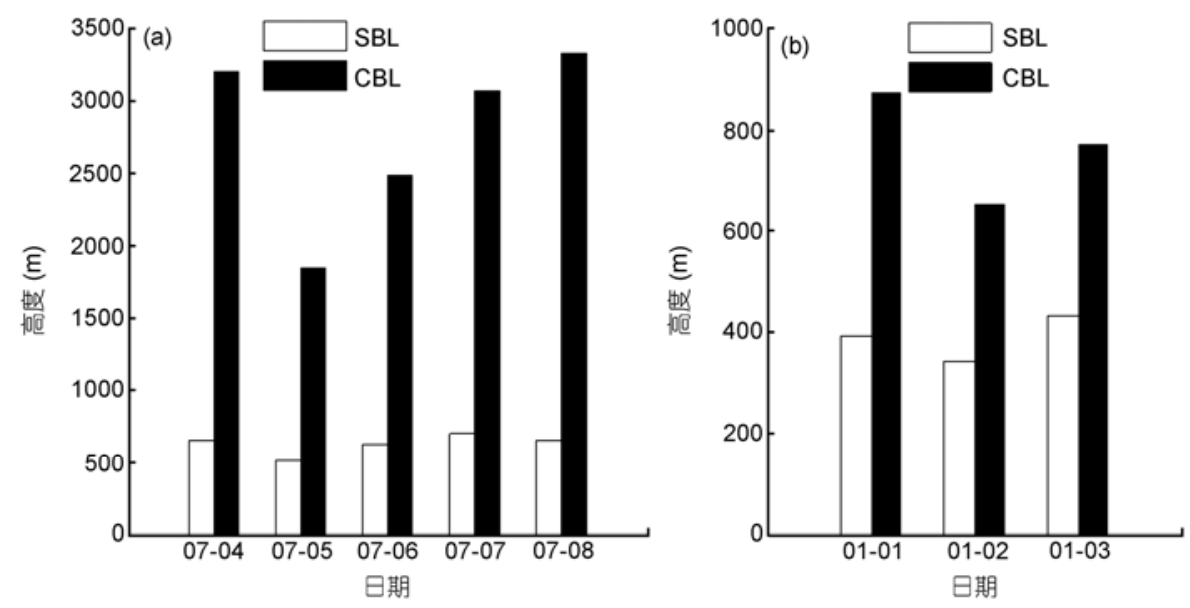

图 8 降水过程前后夏季 $(\mathrm{a})$ 和冬季 $(\mathrm{b})$ 最大对流边界层 $(\mathrm{CBL})$ 和最大稳定边界层 $(\mathrm{SBL})$ 变化
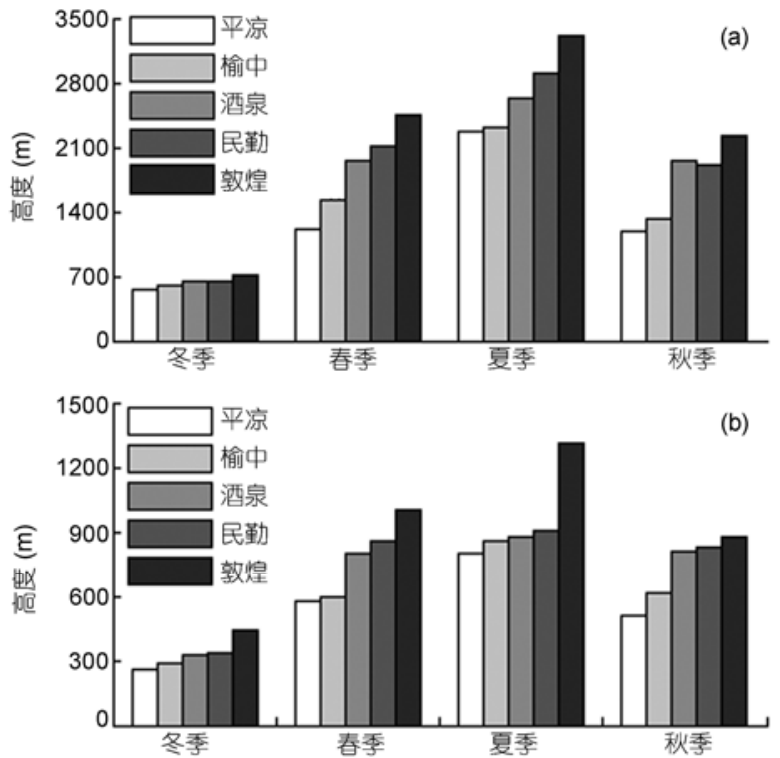

图 9 西北不同对流边界层(a)和稳定边界层(b)高度 的空间分布

最显著，太阳辐射较强时，湍流发展也强烈，边界层 能抬升到比较高的高度. 而随着季节的推移, 太阳高 度角逐渐减小, 地面能获取的总热量逐渐降低, 湍流 发展也受到限制, 边界层高度也随之降低. 冬季, 地 表接收到的能量最小, 温度最低, 热力因子的作用大 大减弱, 且冬季平均风速也小, 湍流和对流运动减弱, 大气扩散能力受限, 阻碍了边界层的发展. 对春季和 秋季而言, 春季的日照时数长, 地面平均温度高, 相 对湿度低, 且春季平均风速均大于秋季, 这些都为大 气边界层的充分发展创造了有利的环境. 同时秋季
冷空气活动频繁, 气温不稳定, 常有极端低温事件发 生, 并多伴有持续性降水, 湿度增大, 不利于大气边 界层高度的抬升。

\section{3 结论与讨论}

(1) 在干旱地区, 由于天空少云, 地面干燥, 不 仅太阳辐射强, 而且陆面热力过程对太阳辐射的响 应十分显著, 其在大气边界层形成和发展过程中的 作用尤为突出. 所以, 无论夏季还是冬季, 地表净辐 射、地-气温差和感热通量日变化过程与大气边界层 厚度均有比较好的对应关系，但由于大气边界层发 展对陆面热力作用的响应需要一定时间, 它们的日 变化位相一般要超前大气边界层 $1 \sim 2 \mathrm{~h}$ 左右.

(2) 在对流边界层发展阶段, 边界层随净辐射、 地-气温差和地表感热通量增加而发展; 但在维持和 衰退阶段, 大气对流边界层随净辐射、地-气温差和地 表感热通量减弱收缩相对比较缓慢, 大多数时候处 于维持状态. 而稳定边界层虽然也随热力作用增强 (或减弱)而扩展(或收缩), 但在发展阶段随地表热力 因素的变化远不如对流边界层敏感.

（3）白天，一般对流边界层突破稳定边界层的限 制进入残余后, 就可以比较顺畅地快速发展. 干旱区 出现深厚对流边界层无疑与白天高净辐射量、大地气温差和强感热通量等极端陆面热力状态有关. 夜间 稳定边界层的发展和维持与陆面热力作用和边界层动 力作用均有一定关联性. 虽然, 从总体上来说净辐射 赤字越强、地-气逆温差越明显和负地表感热通量越大, 
稳定边界层会更厚一些, 但一些较深厚的稳定边界 层个例却也往往出现在地-气逆温差比较小的情况下. 这说明稳定边界层发展机制要更复杂一些, 而且可能 与大风引起的机械湍流扩散对形成深厚稳定边界层的 作用有关. 风速超过 $10 \mathrm{~m} \mathrm{~s}^{-1}$ 的边界层低空急流出现 可能是深厚稳定边界层形成的重要条件之一.

(4) 在中国干旱和半干旱地区, 边界层的厚度随
气候区从极端干旱区向半干旱区过渡而减小.

然而, 由于观测资料分布状态不够广泛和代表 性的不足 ${ }^{[30,31]}$, 大气边界层厚度与陆面热力因素的 某些关联性还没有充分表现出来. 同时, 由于陆面热 力因素往往与大气边界层动力因素耦合在一起, 需 要用对边界层过程描述比较精细的大气数值模式的 模拟实验来进一步深入分析.

致谢感王润元、张立功、刘宏宜、巴秀天等同志参加了本文资料的观测, 并对本文的研究给予了大力支持, 审稿 专家提出了宝贵的修改意见, 在此一并致谢.

\section{参考文献}

1 赵鸣. 大气边界层动力学. 北京: 高等教育出版社, 2006

2 Garratt J R. The Atmospheric Boundary Layer. Cambridge: Cambridge University Press, 1992

3 Raman S, Templeman B, Templeman S, et al. Structure of the Indian southwesterly pre-monsoon and monsoon boundary layers: Observations and numerical simulation. Atmos Environ, 1990, 24: 723-734

4 Gamo M, Goyal P, Manju K, et al. Mixed-layer characteristics as related to the monsoon climate of New Delhi, India. Bound-Layer Meteor, 1994, 67: 213-227

5 Gamo M. Thickness of the convection and large-scale subsidence above deserts. Bound-Layer Meteor, 1996, 79: 265-278

6 Takemi T. Structure and evolution of a severe squall line over the arid region in northwest China. Mon Weather Rev, 1999, 127: 1301-1309

7 张强, 黄荣辉, 王胜, 等. 西北干旱区陆面过程观测野外试验(NWC-ALIEX)及其研究进展. 地球科学进展, 2005, 20: 427-441

8 张强, 卫国安, 侯平. 初夏敦煌荒漠戈壁大气边界结构特征的一次观测研究. 高原气象, 2004, 23: 587-597

9 乔娟, 张强, 张杰, 等. 西北干旱区冬、夏季大气边界层结构对比研究. 中国沙漠, 2010, 30: 422-431

10 Zhang J, Zhang Q. Aerosol impact and correction on temperature profile retrieval from MODIS. Geophys Res Lett, 2008, 35: L13818, doi: 10.1029/2008GL034419

11 Marsham J H, Parker D J , Crams, C M, et al. Obsevations of mseoscale and boundary-layer circulation affecting dust uplift and transport in the Saharan boundary-layer. Atmo Chem Phys Discuss, 2008, 8: 8817-8845

12 Zhang Q, Wang S, Li Y Y. The depth of atmospheric boundary layer in arid region of Northwest China. Acta Meteorol Sin, 2006, 20(Suppl): $1-12$

13 张强. 极端干旱荒漠地区大气热力边界层厚度研究. 中国沙漠, 2007, 27: 614-620

14 张强, 赵映东, 王胜, 等. 极端干旱荒漠区典型晴天大气热力边界层结构分析. 地球科学进展, 2007, 22: 1150-1159

15 张强, 王胜. 西北干旱区夏季大气边界层结构及其陆面过程特征. 气象学报, 2008, 66: 599-608

16 李岩瑛, 钱正安, 薛新玲, 等. 西北干旱区夏半年深厚的混合层与干旱气候形成. 高原气象, 2009, 28: 46-54

17 Takemi T, Satomura M. Numerical experiments on the mechanism for the development and maintenance of long-lived asquall lines in dry environment. J Atmos Sci , 2000, 57: 1718-1740

18 陈玉春, 吕世华, 高艳红. 不同尺度绿洲环流和边界层特征的数值模拟. 高原气象, 2004, 23: 177-183

19 张立功, 张强, 王润元, 等. L 波段雷达在西北干早荒漠区大气边界层观测试验中的应用研究. 地球科学进展, 2007, 22: 162-167

20 张立功, 王汝忠, 黄小明, 等. L 波段测风雷达-电子探空仪系统简介. 甘肃气象, 2002, 4: 30-32

21 中国气象局监测网络司. $\mathrm{L}$ 波段(1 型)高空气象探测系统业务操作手册. 北京: 气象出版社, 2005. 12-18

22 Seibert P, Beyrich F, Gryning S E, et al. Review and intercomparison of operational methods for the determination of the mixing height. Atmos Environ, 2000, 34: 1001-1027

23 Hyun Y K, Kim K E, Ha K J. A comparison of methods to estimate the height of stable boundary layer over atemperate grassland. Agric For Meteorol, 2005,132: 132-142

24 张强, 王胜. 干早荒漠区土壤水热特征和地表辐射平衡年变化规律研究. 自然科学进展, 2007, 17: 211-216 
25 张强, 曹晓彦. 敦煌地区荒漠戈壁地表热量和辐射平衡特征的研究. 大气科学, 2003, 27: 245-254

26 张强. 敦煌绿洲夏季典型晴天地表辐射和能量平衡及小气候特征. 植物生态学报, 2002, 26: 203-213

27 张强. 夏季绿洲生态环境对荒漠背景地表能量过程的扰动. 生态学报, 2005, 25: 2459-2466

28 张强, 王胜. 绿洲与荒漠背景夏季近地面层大气特征的对比分析. 冰川冻土, 2005, 27: 282-289

29 Randal D K, Paul A D, Guo Z C, et al. Regions of strong coupling between soil moisture and precipitation. Am Association Adv Sci, 2004, 305: $1138-1140$

30 张强, 王胜. 关于黄土高原陆面过程及其观测试验研究. 地球科学进展, 2008, 23: 167-143

31 张强, 胡向军, 王胜, 等. 黄土高原陆面过程试验研究(LOPEX)有关科学问题. 地球科学进展, 2009, 24: 363-371 